\title{
CALIDAD MICROBIOLÓGICA DEL AMBIENTE DE LA BIBLIOTECA ALFONSO PATIÑO ROSSELLI, TUNJA- BOYACÁ (COLOMBIA)
}

\section{MICROBIAL QUALITY OF ENVIRONMENT AT ALFONSO PATIÑO ROSSELLI LIBRARY, TUNJA-BOYACÁ (COLOMBIA)}

\author{
Deisy Lisseth Toloza ${ }^{1}$, Luz Marina Lizarazo ${ }^{2}$
}

\begin{abstract}
${ }^{1}$ Bióloga, Universidad Pedagógica y Tecnológica de Colombia, Grupo de Investigación Biología Ambiental, Escuela de Ciencias Biológicas, Avenida Central del Norte, Tunja, Boyacá (Colombia), lisseth77@gmail.com; ${ }^{2}$ Bacterióloga, M.Sc. Ph.D. Universidad Pedagógica y Tecnológica de Colombia, luz.lizarazo@uptc.edu.co
\end{abstract}

Rev. U.D.C.A Act. \& Div. Cient. 16(1): 43 - 52, 2013

\section{RESUMEN}

La calidad del aire en ambientes internos puede estar influenciada por la presencia de agentes abióticos y bióticos, entre los que se encuentran microorganismos, esporas, ácaros y polen, los cuales, son componentes naturales de estos ambientes y pueden ser transportados, desde el exterior, por partículas de polvo. Con este trabajo, se buscó evaluar la presencia de microorganismos en el ambiente de la Biblioteca Alfonso Patiño Rosselli, Tunja (Boyacá) y establecer cuáles de los géneros fúngicos aislados podría representar riesgo de biodeterioro sobre los documentos. Se empleó el método de sedimentación en placa, para el muestreo ambiental, utilizando agar Sabouraud, para el aislamiento de hongos y agar nutritivo, para bacterias, mientras que para el muestreo de libros, se empleó agar papa dextrosa, como medio de cultivo. En el ambiente, la mayor diversidad estuvo representada por los hongos, con 23 géneros aislados, con predominio de Cladosporium spp., mientras que las levaduras fueron menos representativas, siendo Geotrichum, el género predominante. En cuanto a las bacterias, las Gram positivas fueron las más abundantes, siendo Staphylococcus el género más frecuente de los 13 identificados, frente a tres géneros de bacterias Gram negativas. Aspergillus spp. y Penicillium spp. predominaron en las muestras de libros. La concentración microbiana del ambiente fue alta, aunque se encontró dentro del límite de sanidad de lugares públicos, para considerarlos como no contaminados; sin embargo, es importante establecer medidas de control de estas poblaciones microbianas y de las condiciones ambientales que podrían favorecer su desarrollo.

Palabras clave: Aerobiología, calidad microbiológica, enfermedades respiratorias, microorganismos de bibliotecas.

\section{SUMMARY}

Air quality of indoor environments can be influenced by the presence of biotic and abiotic agents such as microorganism, spores, acari, and pollen, natural components in these environments, which can be transported from the outdoor air by dust particles.. The microorganisms present in the environment of the Library Alfonso Patiño Rosselli, Tunja (Boyacá) were evaluated and it was determinated which of the isolated fungal genera could represent risk of biodeterioration on the documents. The open Petri dish sedimentation method was employed for the microbiological sampling, using Sabouraud Agar for fungi isolation and Nutrient Agar for bacteria, whereas for sampling of documents, the Potato Dextrose Agar as culture media was utilized. In the environment, the highest diversity was represented by fungi with 23 isolated genera, predominating Cladosporium spp., whereas yeasts were less representative, with Geotrichum the predominant genus. Regarding bacterial forms, Gram positives were the most abundant, being Staphylococcus the most prevalent genus of the 13 identified ones, with respect to three genera of Gram negative. On books, Aspergillus spp., and Penicillium spp. were the predominant fungi. Microbial concentration of environment was high, but within the limit of sanity of public places to be considered as not contaminated; however, it is important to establish control measures of these microbial populations and the environmental conditions that could favor its development.

Key words: Aerobiology, microbial quality, respiratory diseases, library microorganisms. 


\section{INTRODUCCIÓN}

La presencia de agentes abióticos y bióticos, entre los que se encuentran microorganismos, esporas, ácaros y polen, puede influenciar la calidad del aire en ambientes internos, que logran ser transportados desde el exterior, por partículas de polvo (Labarrere et al. 2003). La concentración de microorganismos en lugares cerrados depende de diversos factores, entre los cuales, la temperatura y la humedad relativa son los principales. Otros, incluyen la microbiota presente en el aire exterior, tipo de edificación y su localización geográfica, número de personas presentes y las actividades que realizan, puntos locales de vegetación, sistemas de ventilación y de limpieza del sitio (Shelton et al. 2002; Jones \& Harrison, 2004; Pyrri \& Kapsanaki-Gotsi, 2007; O'Gorman \& Fuller, 2008; Nevalainen \& Morawska, 2009) y más específicamente, en el caso de bibliotecas y de archivos, puede también influir el estado de preservación de libros y de documentos (Maggi et al. 2000).

Hoy en día, el conocimiento de la contaminación microbiana en ambientes internos es considerado como el mecanismo más elemental de prevención de enfermedades, debido a la influencia de los microorganismos sobre la salud de las personas (Labarrere et al. 2003). Se ha reportado que géneros bacterianos, como Bacillus, Pseudomonas y Staphylococcus (Borrego et al. 2008) y fúngicos, como Alternaria, Aspergillus y Cladosporium pueden provocar diversas enfermedades en el hombre asociadas, principalmente, con problemas respiratorios (Angelosante et al. 2007), en los que la inhalación es la principal vía de infección (Chandra et al. 2005), además de originar irritaciones dérmicas y oculares (Novaresi, 2009).

Las bacterias, se encuentran con mayor frecuencia en espacios internos con respecto a los hongos; sin embargo, representan un menor riesgo en el biodeterioro de documentos, al requerir mayores condiciones de humedad (Valentín et al. 1990). Son varios los estudios que han evaluado la contaminación fúngica en ambientes internos (Hyvärinen et al. 2001; Borrego et al. 2008, 2010a, 2011; Rojas et al. 2008; TolozaMoreno \& Lizarazo-Forero, 2011), encontrando, como los más frecuentes, los géneros Aspergillus, Cladosporium, Mucor y Penicillium.

Por otro lado, autores como Gallo (1993), Borrego et al. (2008, 2010a) han demostrado que la mayoría de hongos de ambientes internos presentan actividad celulolítica, proteolítica y amilolítica, producen ácidos, excretan pigmentos y forman biopelículas sobre el papel, lo que acelera su deterioro en condiciones de temperatura y de humedad adecuadas de almacenamiento.

En esta investigación, se evaluó la presencia de microorga- nismos en el ambiente de la Biblioteca Alfonso Patiño Rosselli, Tunja-Boyacá y se determinaron cuáles géneros fúngicos podrían estar representando riesgo de biodeterioro sobre los documentos que allí se encuentran.

\section{MATERIALES Y MÉTODOS}

Área de estudio. La calidad microbiológica del ambiente, se evaluó en la Biblioteca Alfonso Patiño Rosselli, ubicada en el Claustro de San Agustín, Tunja-Boyacá (Colombia). La biblioteca fue fundada en 1984 por el Banco de la República y cuenta, hoy en día, con una colección de aproximadamente 52.000 títulos (Centro Virtual de Noticias, 2006).

Aislamiento de microorganismos. La concentración microbiológica del ambiente de la biblioteca, se evaluó realizando seis muestreos en períodos distintos de 2011, en los cuales, se empleó el método gravimétrico de sedimentación en placa propuesto por Omeliansky (Bogomolova \& Kirtsideli, 2009). Se establecieron en total cinco puntos de muestreo, siguiendo un modelo diagonal.

Cada punto fue muestreado por triplicado, por cada medio de cultivo, con exposición al ambiente por 30 minutos de cajas de Petri $(90 \mathrm{~mm})$, con agar glucosa de Sabouraud, suplementado con cloranfenicol, para el aislamiento de hongos y agar nutritivo, para bacterias. Las cajas fueron ubicadas a una altura aproximada de 2,0 m del suelo y los muestreos se realizaron hacia las 10:00 horas. Adicionalmente, se tomaron datos de temperatura y de humedad relativa del ambiente, empleando un Medidor Atmosférico-Davis ${ }^{\circledR}$.

Las cajas con agar glucosa de Sabouraud fueron incubadas a $28 \pm 2^{\circ} \mathrm{C}$, entre cinco y siete días y las de agar nutritivo, a $35 \pm 2^{\circ} \mathrm{C}$, por 24 a 72 horas. Posteriormente, se cuantificaron las unidades formadoras de colonia por metro cúbico de aire (UFC $\left.\mathrm{m}^{-3}\right)$, tanto para mohos, levaduras y bacterias, con previa realización de tinción de Gram, para distinguir entre bacterias y levaduras que crecieron en las cajas de agar nutritivo, de acuerdo a la fórmula propuesta por Omeliansky (Bogomolova \& Kirtsideli, 2009):

$$
\mathrm{N}=5 \mathrm{a} \times 10^{4}(\mathrm{bt})^{-1}
$$

donde: N: UFC $\mathrm{m}^{-3}$ de aire en el ambiente, a: número de colonias por caja de Petri, b: superficie de la caja de Petri $\left(\mathrm{cm}^{2}\right)$, t: tiempo de exposición (minutos).

Se halló la densidad relativa (DR) de los géneros microbianos aislados, de acuerdo con la fórmula de Smith (Borrego et al. 2010a):

$\mathrm{DR}=$ (Número de colonias del género o especie / Número total de colonias de todos los géneros o especies) * 100 
Aislamiento de hongos a partir de libros. En un muestreo adicional (muestreo siete), se tomó aleatoriamente una muestra representativa del total de libros de la biblioteca, con un intervalo de confianza del $90 \%$. Las muestras se tomaron con hisopos estériles humedecidos en solución de Cloruro de Sodio ( $\mathrm{NaCl}$ 0,85\%). Cada documento fue muestreado por duplicado y se empleó agar papa dextrosa (PDA), como medio de cultivo. Las cajas se incubaron a $28 \pm 2{ }^{\circ} \mathrm{C}$ por siete días.

Identificación de microorganismos aislados. Cada morfotipo aislado fue descrito macroscópicamente. Los aislados fúngicos se describieron al microscopio y se realizaron montajes con azul de lactofenol, mediante la técnica de impronta (Schaechter et al. 2006) y microcultivos, y para su identificación hasta género, se utilizaron las claves taxonómicas de Barnett (1960) y Domsh et al. (1980a, b). Las levaduras fueron descritas con tinción de Gram y montajes en fresco entre lámina y laminilla con azul de lactofenol e identificadas de acuerdo con Carrillo (2003) y Kirk et al. (2008).

Las características microscópicas de las bacterias y su identificación hasta género, se determinaron por tinción de Gram y siembra en medios selectivos y pruebas bioquímicas convencionales. Los resultados, se corroboraron con las características bioquímicas, señaladas por Finegold \& Martin (1983) y Madigan et al. (2006).
Análisis estadístico. Para establecer diferencias estadísticas significativas entre la concentración microbiológica del aire en el interior de la biblioteca a lo largo del estudio en los diferentes muestreos, se empleó un ANOVA multifactorial, con un nivel de significancia del 0,05 y se hizo la transformación de los datos, para cumplir con el supuesto de homoceasticidad. Se empleó el programa estadístico R Versión 2.14.1.

\section{RESULTADOS Y DISCUSIÓN}

Humedad relativa y temperatura del ambiente. En el interior de la biblioteca, se registró en promedio una humedad relativa de $59,0 \%( \pm 5,10)$ y una temperatura de $19,7^{\circ} \mathrm{C}( \pm 4,84)$. Estas variables fueron constantes a lo largo del muestreo, en los distintos períodos del año, los cuales, presentaron, en general, estación seca. En julio, se evidenció la mayor humedad, mientras que la mayor temperatura se registró en mayo y noviembre (Tabla 1).

La humedad relativa se encontró en el límite del rango óptimo, señalado por Gallo (1993), quien considera que entre un $60-90 \%$ se puede dar el desarrollo de hongos y causar alteraciones en documentos y es menor al $85 \%$, requerida para el crecimiento bacteriano. Entre tanto, la temperatura del ambiente fue adecuada, al considerar que la apropiada para almacenar documentos impresos y en formato electrónico está entre 16 y $21^{\circ} \mathrm{C}$ y entre 18 y $20^{\circ} \mathrm{C}$, respectivamente,

Tabla 1. Humedad relativa (HR) y temperatura $\left({ }^{\circ} \mathrm{T}\right)$ registradas en el ambiente interno de la biblioteca Alfonso Patiño Rosselli. Se muestra el promedio aritmético y la desviación estándar ( \pm ) de cada variable.

\begin{tabular}{|c|c|c|c|}
\hline Muestreo & Mes $*$ & HR (\%) & ${ }^{\circ} \mathbf{T}\left({ }^{\circ} \mathbf{C}\right)$ \\
\hline 1 & Enero & $50,82( \pm 3,17)$ & $19,41( \pm 0,72)$ \\
\hline 2 & Mayo & $58,47( \pm 3,25)$ & $20,00( \pm 1,50)$ \\
\hline 3 & Junio & $61,10( \pm 3,06)$ & $18,58( \pm 1,39)$ \\
\hline 4 & Julio & $63,07( \pm 2,81)$ & $18,52( \pm 0,50)$ \\
\hline 5 & Agosto & $60,67( \pm 1,84)$ & $19,41( \pm 0,57)$ \\
\hline 6 & Noviembre & $62,25( \pm 0,96)$ & $20,00( \pm 0,64)$ \\
\hline 7 & & & $19,69( \pm 4,84)$ \\
& & $59,00( \pm 5,10)$ & \\
\hline
\end{tabular}

*Para realizar los muestreos, se establecieron tres períodos distintos del año: uno al principio, otro a mitad de año y otro al final, buscando establecer posibles variaciones de concentraciones microbianas en el ambiente. 
con el fin de que no se presente deterioro por microorganismos (Borrell et al. 2005). La contaminación microbiana de ambientes internos puede ser favorecida por factores, como humedad elevada, ventilación reducida y temperatura, un sustrato como papel que proporcione, principalmente a los hongos, nutrientes necesarios, como celulosa (Aira et al. 2006) y por la presencia de polvo (Shelton et al. 2002).

Contaminación microbiana. El mayor porcentaje de microorganismos correspondió a las formas fúngicas, con un $44,9 \%$, mientras que las bacterias y levaduras, en un $41,5 \%$ y $13,6 \%$, respectivamente. Asimismo, los mohos representaron la mayor diversidad, aislándose 23 géneros, en una concentración entre 31,4 y 139,7 UFC m ${ }^{-3}$.

La concentración microbiana de la biblioteca fue similar a la reportada por autores, como Borrego et al. (2008, 2010a, b); Bogomolova \& Kirtsideli (2009) y Toloza-Moreno \& Lizarazo-Forero (2011), quienes han evaluado la calidad microbiana en ambientes cerrados, mediante la técnica de se- dimentación en placa; sin embargo, esta concentración fue inferior a la señalada por la Organización Mundial de la Salud (Nevalainen \& Morawska, 2009), que considera un ambiente interno contaminado aquel que presente una concentración microbiana superior a 1000 UFC $\mathrm{m}^{-3}$.

Caracterización fúngica en el ambiente. No se presentaron diferencias estadísticamente significativas de las UFC fúngicas aisladas entre los diferentes muestreos $\left(F_{5,84}=13,289\right.$, $\mathrm{p}=1,537 \mathrm{e}-09$ ). El género predominante fue Cladosporium (21,0\%), seguido de Acremonium (15,7\%) y Penicillium $(12,9 \%)$, mientras que los demás géneros aislados presentaron una porcentaje de alrededor del $10 \%$ o menos (Figura 1).

La abundancia de esporas de Cladosporium spp. fue mayor en el primer muestreo, a partir del cual, se presentó una disminución hasta el final del estudio, con una concentración de UFC, que osciló entre 62,9 y 1,7 UFC $\mathrm{m}^{-3}$. Para los géneros Acremonium y Penicillium, la variación mensual en la concentración de esporas no fue constante, siendo mayor en

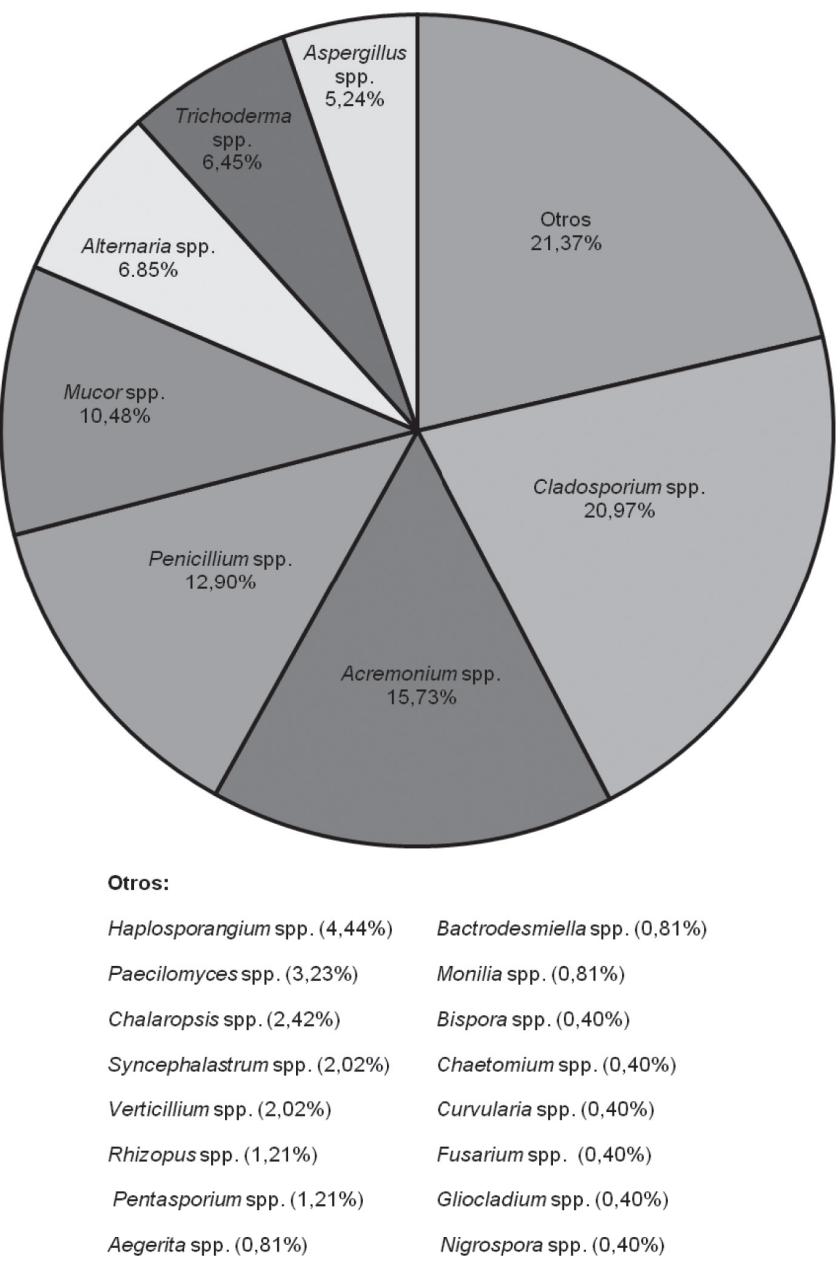

Figura 1. Densidad relativa de los géneros fúngicos aislados en el ambiente de la Biblioteca Alfonso Patiño Rosselli. 
noviembre, con 24,5 UFC m² ${ }^{-3}$, para los dos géneros, cuando se registró una alta humedad relativa y alta temperatura del ambiente $\left(62,3 \%, 20{ }^{\circ} \mathrm{C}\right.$, respectivamente) y fue menor, para Acremonium, en junio y para Penicillium, en agosto, con 1,7 UFC $\mathrm{m}^{-3}$, cuando se presentó la menor humedad registrada (Figura 2).

Cladosporium y Penicillium fueron los géneros fúngicos más representativos en el ambiente y han sido también reportados por otros autores en ambientes internos (Pitzurra et al. 1999; Shelton et al. 2002; Aira et al. 2006; Borrego et al. 2008, 2010a, b; Rojas et al. 2008; Bogomolova \& Kirtsideli, 2009; Toloza-Moreno \& Lizarazo-Forero, 2011). Estos géneros incluyen especies patógenas oportunistas de importancia en salud pública, al estar asociados con enfermedades respiratorias alérgicas, especialmente, asma y rinitis (Kurup et al. 2000; Haleem Khan et al. 2009; Nevalainen \& Morawska, 2009). Acremonium también fue predominante; sin embargo, a pesar que de igual forma se ha aislado en otros estudios (Nugari \& Roccardi, 2001), no se ha registrado en alta frecuencia en el ambiente.

La concentración de levaduras aisladas, se registró entre 7,0 y 43,7 UFC m m $^{-3}$ con Geotrichum, como género predominante y, en menor proporción, Rhodotorula y Candida. El número no fue estadísticamente significativo durante los distintos muestreos $\left(\mathrm{F}_{5,84}=3,3642, \mathrm{p}=0,008083\right)$; no obstante, su abundancia varió entre los muestreos, en donde Geotrichum spp. fue más frecuente en agosto, con 38,4 UFC $\mathrm{m}^{-3}$, cuando se presentó una humedad de $60,7 \%$, mientras que Rhodotorula spp., se evidenció con mayor frecuencia en enero y julio, con 7,0 UFC $\mathrm{m}^{-3}$. Los aislamientos de Candida spp. fueron escasos, registrados únicamente en enero y en mayo.

Caracterización bacteriana en el ambiente. Se registraron once géneros bacterianos, en una concentración entre 33,2 y 118,8 UFC m$^{-3}$. Las UFC bacterianas no variaron estadística-
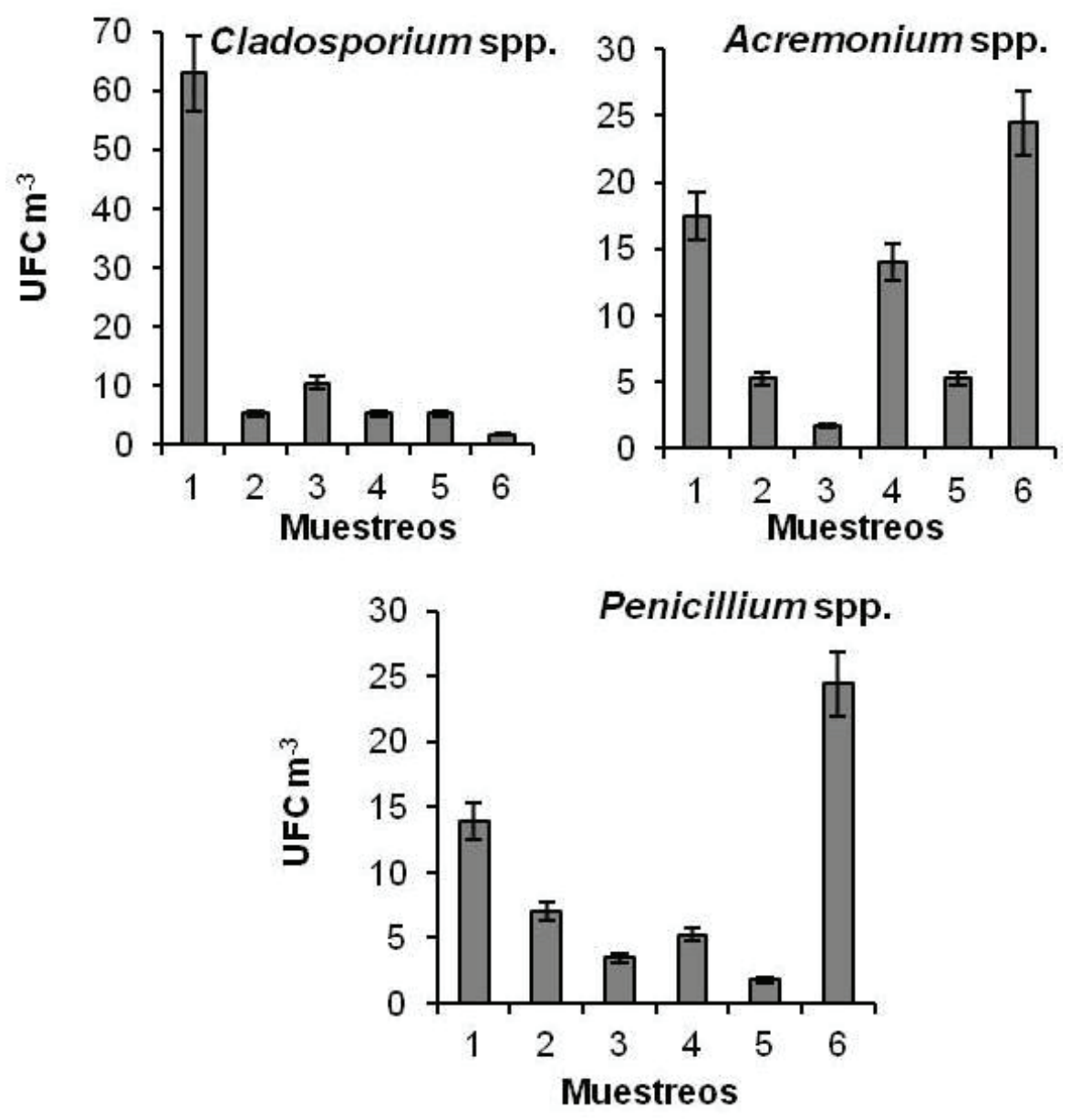

Figura 2. Variación en la concentración de los géneros fúngicos predominantes en el interior de la Biblioteca Alfonso Patiño Rosselli. Las barras representan el error estándar de la media. 
mente durante el muestreo $\left(\mathrm{F}_{5,84}=5,7227, \mathrm{p}=0,0001363\right)$; sin embargo, las bacterias Gram positivas predominaron con un $92,1 \%$, con respecto a las bacterias Gram negativas aisladas.

Una mayor prevalencia de bacterias Gram positivas ha sido registrada también por Borrego et al. (2008, 2010a, b) y se ha reportado que producen varias de las enfermedades bacterianas trasmitidas por el aire, principalmente, a su mayor supervivencia en este ambiente (Zhu et al. 2003). También pueden ingresar al interior de los locales a causa de la actividad del hombre, ya que muchas de ellas se encuentran en la piel y en las mucosas (Borrego et al. 2008) y pueden ser transportadas por el polvo presente en el piso (Goh et al. 2000).

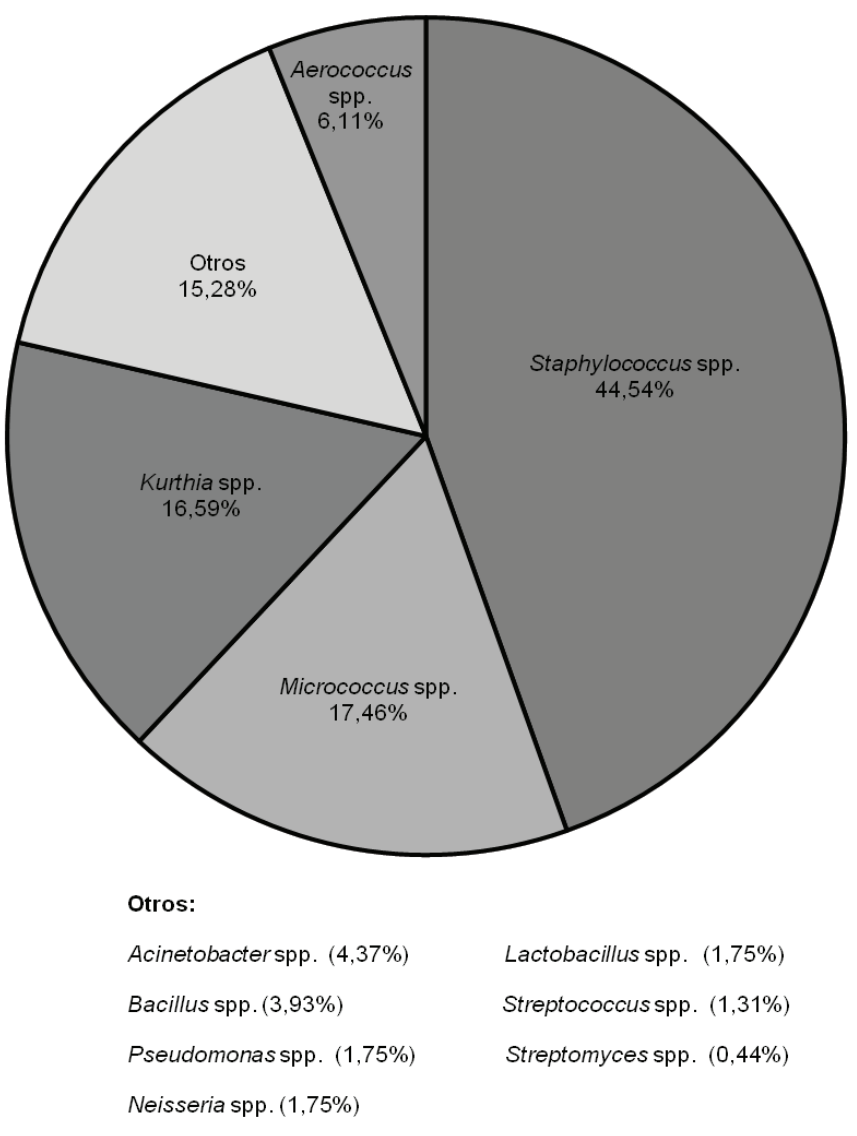

Figura 3. Densidad relativa de los géneros bacterianos aislados en el ambiente de la Biblioteca Alfonso Patiño Rosselli.
El género bacteriano con mayor abundancia fue Staphylococcus (44,5\%), seguido de Micrococcus y Kurthia, con un 17,5 y $17,0 \%$, respectivamente. Aerococcus spp., se registró en un $6,1 \%$, mientras que los siete géneros restantes, se presentaron en menos del 5,0\% (Figura 3). Staphylococcus spp., se registró durante el muestreo, aislándose principalmente en julio, con 45,4 UFC m${ }^{-3}$ (Figura 4). Entre las bacterias Gram negativas, se aislaron los géneros Acinetobacter, Pseudomonas y Neisseria, que se presentaron en baja densidad. Los géneros Staphylococcus, Micrococcus, Bacillus, Streptococcus han sido también aislados en otros ambientes cerrados (Labarrere et al. 2003; Borrego et al. 2008, 2010a, b) y algunas de sus especies están asociadas con problemas, básicamente, respiratorios (Borrego et al. 2010a).
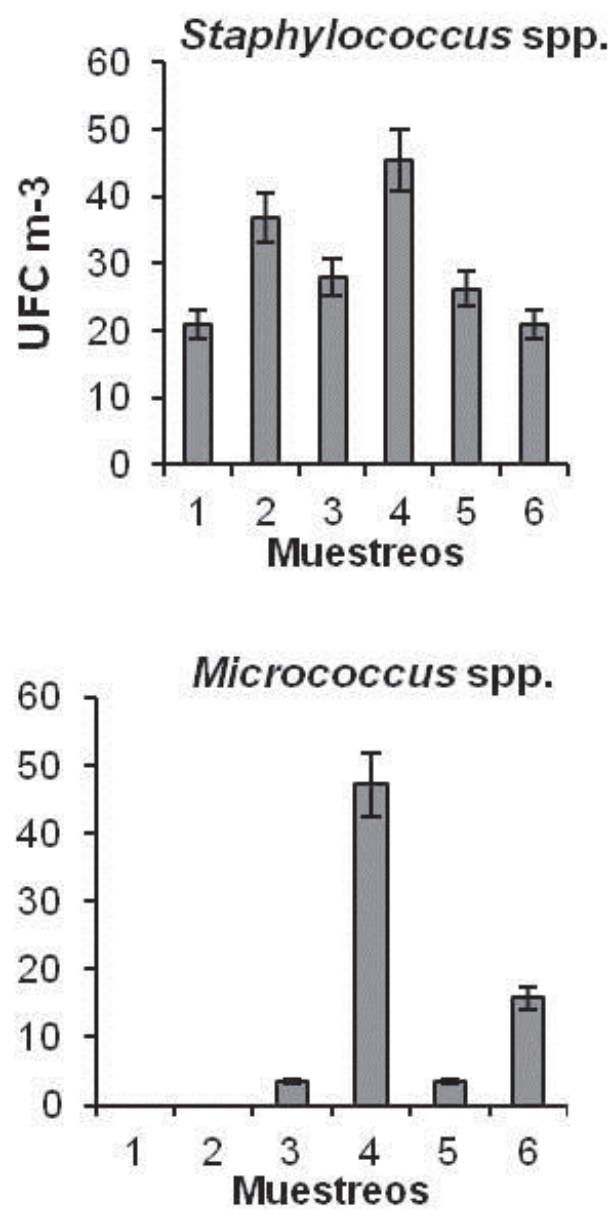

Figura 4. Variación en la concentración de los géneros bacterianos predominantes en el interior de la Biblioteca Alfonso Patiño Rosselli. Las barras representan el error estándar de la media. 
Carga fúngica aislada de la colección bibliográfica. Se aislaron en total nueve géneros de hongos filamentosos, a partir de 166 colonias aisladas. La figura 5 muestra que el género Aspergillus fue el más aislado, representando un $36,1 \%$ del total de las colonias fúngicas, seguido de Penicillium spp. (18,7\%) y Trichoderma spp. (16,9\%). También, se aislaron hongos con una importante actividad celulolítica, como Cladosporium, Alternaria, Chaetomium, que junto a los géneros Aspergillus y Penicillum representan un riesgo para las colecciones de libros y de documentos (Zyska, 1997; Florian \& Manning, 2000; Szczepanowska \& Cavaliere, 2000, Gorbushina et al. 2004).

La degradación del papel involucra la descomposición de tintas orgánicas y de aditivos (encolantes, abrillantadores ópticos), apresto (almidón o proteína) y revestimientos, además de las fibras de celulosa. Entre los agentes microbianos más importantes implicados en el biodeterioro de documentos almacenados, se encuentran los hongos (Rojas et al. 2009) y su desarrollo en el papel está regulado por las condiciones de temperatura y de humedad del sitio de almacenamiento (Giraldo et al. 2009).
La presencia de los géneros Aspergillus y Penicillium en los libros, se podría relacionar con su prevalencia en el ambiente de la biblioteca, a pesar de no haber sido los más abundantes. Se conoce que estos géneros son ubicuos y presentan elevada adaptabilidad metabólica (Zyska, 1997; Lugauskas et al. 2003) y han sido reportados, junto a otros, como responsables de biodeterioro de materiales orgánicos (Nugari \& Roccardi, 2001; Borrego et al. 2011). Asimismo, Valentín et al. (1990) mencionan que los hongos germinan en papel en temperaturas de $14^{\circ} \mathrm{C}$ a $35^{\circ} \mathrm{C}$ y humedad superior al $65 \%$.

Algunos autores han detectado y caracterizado compuestos metabólicos volátiles producidos por la actividad de los hongos sobre el papel (Canhoto et al. 2004). Los géneros Alternaria, Chaetomium y Cladosporium identificados en este estudio, se caracterizan por la producción de diferentes enzimas implicadas en patogénesis de plantas, que podrían ser extrapolados en el proceso de biodeterioro del papel, así como se ha detectado actividad enzimática en la producción de proteasas y de amilasas, por parte de estos géneros (Das et al. 1997; Baraznenok et al. 1999; Rojas et al. 2009). Para futuras investigaciones, se pretende realizar la determinación

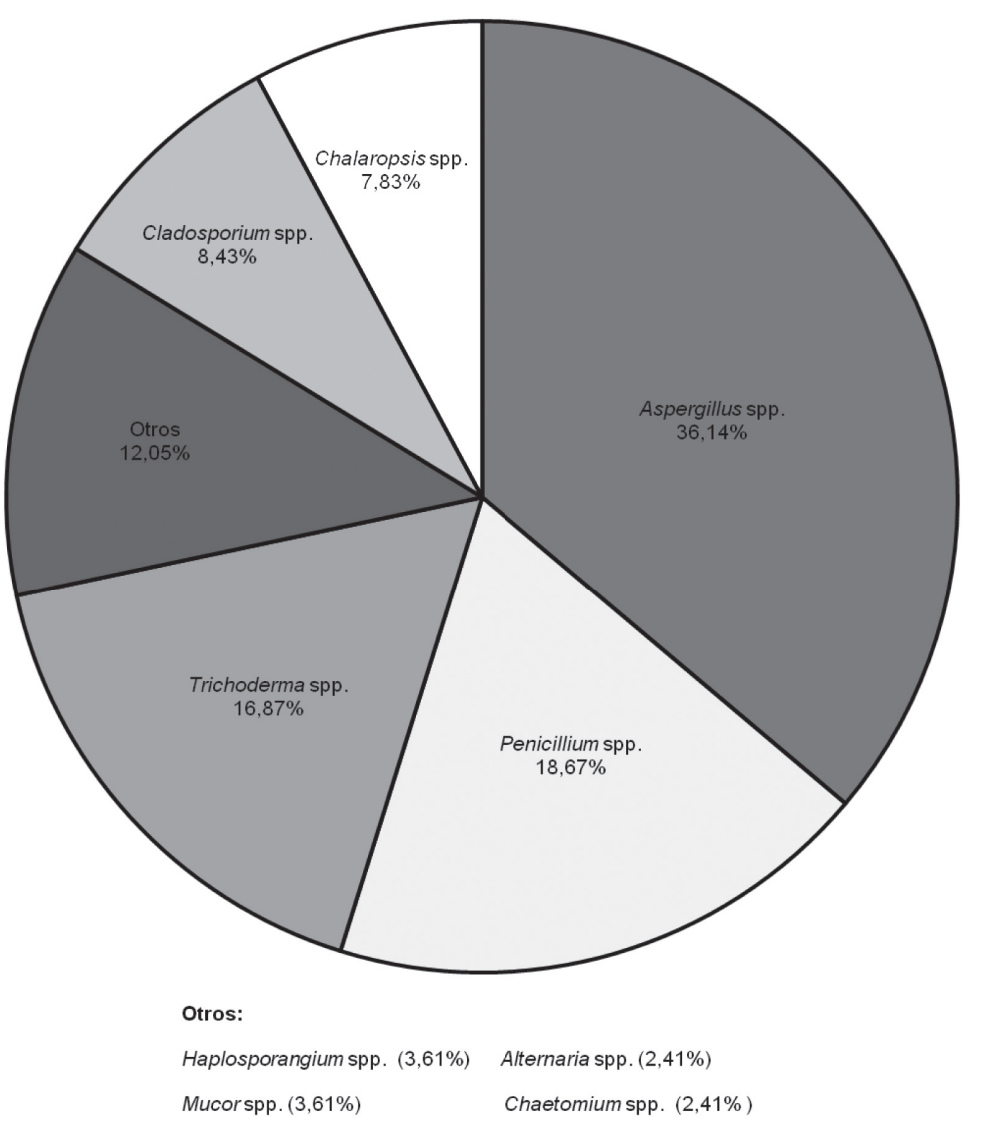

Figura 5. Densidad relativa de los géneros fúngicos aislados de la colección bibliográfica. 
de los agentes causales hasta el nivel de especie, así como el mecanismo que podrían estar causando el biodeterioro de los documentos.

A pesar que la concentración microbiana de la biblioteca no es superior a 1000 UFC $\mathrm{m}^{-3}$, para considerarla como un ambiente contaminado, es importante controlar las poblaciones de microorganismos presentes en el ambiente (Giraldo et al. 2009) y, de igual manera, controlar las condiciones de temperatura y de humedad relativa, mediante el empleo de humificadores o ventiladores, que podrían favorecer su desarrollo. Aspectos como el tiempo de exposición de las personas al ambiente y sus características inmunológicas podrían incidir en la sintomatología de enfermedades respiratorias (Nevalainen \& Morawska, 2009), por lo que el aislamiento de los microorganismos presentes en ambientes cerrados es fundamental para desarrollar programas de control y de prevención de la salud del personal y para evitar el biodeterioro del material bibliográfico.

Agradecimientos: Los autores agradecen al Departamento Administrativo de Ciencia, Tecnología e Innovación "Colciencias" y a la Dirección de Investigaciones de la Universidad Pedagógica y Tecnológica de Colombia por la Beca Pasantía, otorgada dentro del Programa Jóvenes Investigadores e Innovadores "Virginia Gutiérrez de Pineda", para desarrollar este proyecto. Al Banco de la República y a la doctora Amparo Bello, por el permiso para realizar el muestreo; al fitopatólogo Jorge Blanco, por sus orientaciones y corroboración en la identificación de algunos géneros fúngicos y a la Estadística Martha Parada, por su colaboración en el manejo estadístico de los datos. Conflictos de interés: El manuscrito fue preparado y revisado con la participación de todos los autores, quienes declaramos que no existe ningún conflicto de interés que ponga en riesgo la validez de los resultados presentados.

\section{BIBLIOGRAFÍA}

1. AIRA, M.; RODRÍGUEZ, F.; JATO, V.; PIONTELLI, E. 2006. Análisis cuantitativo y cualitativo de la aeromicota aislada de la catedral de Santiago de Compostela (Galicia, España). Bol. Micol. (España). 21:2734.

2. ANGELOSANTE, A.; PACE, L.; TOMASSETTI, B.; COPPOLA, E.; VERDECCHIA, M.; PACIONI, G.; VISCONTI, G. 2007. Estimation of fungal spore concentrations associated to meteorological variables. Aerobiol. (Italia). 23:221-228.

3. BARAZNENOK, V.; BECKER, E.; ANKUDIMOVA, N.; OKUNEV, N. 1999. Characterization of neutral xylanases from Chaetomium cellulolyticum and their biobleaching effect on eucalyptus pulp. EMT (Estados Unidos). 25(8-9):651-659.

4. BARNETT, H. 1960. Illustrated genera of imperfect fungi. $2^{\text {nd }}$ ed. Ed. Burgess Publ. Co. (Estados Unidos). 225p.

5. BOGOMOLOVA, E.; KIRTSIDELI, I. 2009. Airborne fungi in four stations of the St. Petersburg Underground railway system. Int. Biodet. Biodegrad. (Estados Unidos). 63:156-160.

6. BORREGO, S.; PONS, V.; PERDOMO, I. 2008. La contaminación microbiana del aire en dos depósitos del Archivo Nacional de la República de Cuba. Rev. CENIC Cienc. Biol. (Cuba). 39(1):63-69.

7. BORREGO, S.; GUIAMET, P.; GÓMEZ DE SARAVIA, S.; BATISTINI, P.; GARCÍA, M.; LAVIN, P.; PERDOMO, I. 2010a. The quality of air at archives and the biodeterioration of photographs. Int. Biodet. Biodegrad. 64:139-145.

8. BORREGO, S.; PERDOMO, I.; GUIAMET, P.; GÓMEZ DE SARAVIA, S. 2010b. Estudio de la concentración microbiana en el aire de depósitos del Archivo Nacional de Cuba. Augmdomus (Uruguay). 1:118-137.

9. BORREGO, S.; PERDOMO, I.; DE LA PAZ, J.; GÓMEZ DE SARAVIA, S.; GUIAMET, P. 2011. Relevamiento microbiológico del aire y de materiales almacenados en el Archivo Histórico del Museo de La Plata, Argentina y en el Archivo Nacional de la República de Cuba. Rev. Museo de La Plata, Sección Botánica (Argentina). 18(119):1-18.

10. BORRELL, A.; CUETO, A.; CASTILLO, D.; MAZORRA, Y. 2005. Lineamientos para la conservación de documentos en la Biblioteca Médica Nacional de Cuba. Disponible desde Internet en: http://scielo.sld.cu/pdf/ aci/v12n5/aci12504.pdf (con acceso el 01/04/2012).

11. Centro Virtual de Noticias CVN. 2006. Bibliotecas de Tunja son insuficientes para la demanda de la comunidad. Artículo del Centro Virtual de Noticias. Disponible desde Internet en: http://www.mineducacion. gov.co/cvn/1665/fo-article-98558.pdf (con acceso el $12 / 10 / 2011)$.

12. CANHOTO, O.; PINZARI, F.; FANELLI, C.; MAGAN, N. 2004. Application of electronic nose technology for the detection of fungal contamination in library paper. Int. Biodet. Biodegrad. 54(4):303-309. 
13. CARRILLO, L. 2003. Los hongos de los alimentos y forrajes. Ed. Universidad Nacional de Salta (Argentina). $118 p$.

14. CHANDRA, P.; VENKATA-MOHAN, S.; JAYARAMAREDDY, S. 2005. Assessment of microbial (bacteria) concentrations of ambient air at semi-arid urban region: influence of meteorological factors. Appl. Ecol. Environm. Res. (Hungría). 3(2):139-149.

15. DAS, M.K.L.; PRASAD, J.S.; AHMAD, S.K. 1997. Endoglucanase production by paper degrading mycoflora. Letters in Applied Microbiology. 25:313-315.

16. DOMSH, K.; GAMS, W.; ANDERSON, T. 1980a. Compendium of soil fungi. Vol. 1, Parte I. Ed. Academic Press (Estados Unidos). 860p.

17. DOMSH, K.; GAMS, W.; ANDERSON, T. 1980b. Compendium of soil fungi. Vol. 1, Parte II. Ed. Academic Press (Estados Unidos). 406p.

18. FINEGOLD, S.; MARTIN, W. 1983. Diagnóstico Microbiológico. $6^{\text {th }}$ ed. Ed. Médica Panamericana S.A. (Estados (Unidos). 670p.

19. FLORIAN, M.L.E.; MANNING, L. 2000. SEM analysis of irregular fungal fox spots in an 1854 book: population dynamics and species identification. Int. Biodet. Biodegrad. 46(3):205-220.

20. GALLO, F. 1993. Aerobiological research and problems in libraries. Aerobiol. 9:117-130.

21. GIRALDO, M.; TORRES, C.; DÍAZ, J. 2009. Aislamiento de hongos celulolíticos causantes del biodeterioro de la Biblioteca Central de la Universidad del Valle (Cali-Colombia). Rev. Mex. Micol. 29:9-14.

22. GOH, I.; OBBARD, J.; VISWANATHAN, S.; HUANG, Y. 2000. Airborne bacterial and fungal spores in the indoor environment. A case study in Singapore. Acta Biotechn. 20:67-73.

23. GORBUSHINA, A.; HEYRMAN, J.; DORNIEDEN, T.; GONZALEZ-DELVALLE, M.; KRUMBEIN, W.E.; LAIZ, L.; PETERSEN, K.; SAIZ-JIMENEZ, C.; SWINGS, J. 2004. Bacterial and fungal diversity and biodeterioration problems in mural painting environments of St. Martins church (Greene-Kreiensen, Germany). Int. Biodet. Biodegrad. 53(1):13-24.

24. HALEEM KHAN, A.; KARUPPAYIL, S.; MANOHARACHARY, C.; KUNWAR. L.; WAGHRAY, S. 2009. Iso- lation, identification and testing for allergenicity of fungi from air-conditioned indoor environments. Aerobiol. 25:119-123.

25. HYVÄRINEN, A.; VAHTERISTO, M.; MEKLIN, T.; JANTUNEN, M.; NEVALAINEN, A.; MOSCHANDREAS, D. 2001. Temporal and spatial variation of fungal concentrations in indoor air. Aerosol Sci. Techn. (Estados Unidos). 35:688-695.

26. JONES, A.; HARRISON, R. 2004. The effects of meteorological factors on atmospheric bioaerosol concentrations-a review. Sci. Total Environm. (Estados Unidos). 326(1-3):151-180.

27. KIRK, P.; CANNON, P.; MINTER, D.; STALPERS, J. 2008. Dictionary of the Fungi. $10^{\text {th }}$ ed. Ed. CABI (Wallingford). 609p.

28. KURUP, V.; SHEN, H.; BANERJEE, B. 2000. Respiratory fungal allergy. Microb. Infect. (Francia). 2:11011110.

29. LABARRERE, N.; GÓMEZ, A.; AVILA, I.; GUEVARA, M.; FERNÁNDEZ, B. 2003. Riesgos biológicos en ambientes confinados. Rev. Cubana Salud y Trabajo. 4(1-2):4-7.

30. LUGAUSKAS, A.; LEVINSKAITE, L.; PECIULYTE, D. 2003. Micromycetes as deterioration agents of polymeric materials. Int. Biodet. Biodegr. 52:233-242.

31. MADIGAN, M.; MARTINKO, J.; PARKER, J. 2006. Brock Biology of Microorganisms. $11^{\text {a }}$ ed. Ed. Prentice Hall Iberia (España). 1088p.

32. MAGGI, O.; PERSIANI, A.; GALLO, F.; VALENTI, P.; PASQUARIELLO, G.; SCLOCCHI, M.; SCORRANO, M. 2000. Airborne fungal spores in dust present in archives: proposal for a detection method, new for archival materials. Aerobiol. 16:429-434.

33. NEVALAINEN, A.; MORAWSKA, L (ed). 2009. Biological agents in indoor environments. Assessment of health risks. Organización Mundial de la Salud. 206p. Disponible desde Internet en: http://www.ilaqh.qut.edu. au/Misc/BIOLOGICAL AGENTS 2009.pdf (con acceso el 16/04/2011).

34. NOVARESI, M. 2009. Moho: Pautas para el manejo de materiales documentarios contaminados. Bol. Conserv. Restaur. (Argentina). 2(4):9-14. Disponible desde Internet en: http://www.ilam.org/ILAMDOC/BoletinINTI/restN.IV.pdf (con acceso el 16/04/2011). 
35. NUGARI, M.; ROCCARDI, A. 2001. Aerobiological investigations applied to the conservation of cultural heritage. Aerobiol. 17:215-223.

36. O'GORMAN, C.; FULLER, H. 2008. Prevalence of culturable airborne spores of selected allergenic and pathogenic fungi in outdoor air. Atmosph. Environm. (Estados Unidos). 42:4355-4368.

37. PITZURRA, L.; BELLEZZA, T.; GIAMMARIOLI, M.; GIRALDI, M.; SBARAGLIA, G.; SPERA G.; BISTONI, F. 1999. Microbial environmental monitoring of the refectory in the monastery of St. Anna in Foligno, Italy. Aerobiol. 15:203-209.

38. PYRRI, I.; KAPSANAKI-GOTSI, E. 2007. A comparative study on the airborne fungi in Athens, Greece, by viable and non-viable sampling methods. Aerobiol. 23:3-15.

39. ROJAS, T.; MARTÍNEZ, E.; AIRA, M.; ALMAGUER, M. 2008. Aeromicota de ambientes internos: comparación de métodos de muestreo. Bol. Micol. 23:67-73.

40. ROJAS, J.; CRUZ, C.; MIKAN, J.; VILLALBA, L.; CEPERO DE GARCIA, M.; RESTREPO, S. 2009. Isoenzyme characterization of proteases and amylases and partial purification of proteases from filamentous fungi causing biodeterioration of industrial paper. Int. Biodet. Biodegrad. 63(2):169-175.

41. SCHAECHTER, M.; NEIDHARDT, F.; INGRAHAM, J. 2006. Microbe. Ed. Am. Soc. Microbiol. (Estados Unidos). 610p.
42. SHELTON, B.; KIRKLAND, K.; FLANDERS, W.; MORRIS, G. 2002. Profiles of airborne fungi in buildings and outdoor environments in the United States. Appl. Environm. Microbiol. 68:1743-1753.

43. SZCZEPANOWSKA, H.; CAVALIERE, A.R. 2000. Fungal deterioration of 18 th and $19^{\text {th }}$ century documents: a case study of the Tilghman Family Collection, Wye House, Easton, Maryland. Int. Biodet. Biodegrad. 46 (3):245-249.

44. TOLOZA-MORENO, D.; LIZARAZO-FORERO, L. 2011. Aeromicrobiología del Archivo Central de la Universidad Pedagógica y Tecnológica de Colombia (TunjaBoyacá). Acta Biol. Col. 16(1):185-194.

45. VALENTÍN, N.; LISTROM, M.; PREUSSER, F. 1990. Microbial control by low oxygen and low relative humidity environment. Studies in Conservation. 35:222-230.

46. ZHU, H.; PHELAN, P.; DUAN, T.; RAUPP, G.; FERNANDO, H.; CHE, F. 2003. Experimental study of indoor and outdoor airborne bacterial concentrations in Tempe, Arizona, USA. Aerobiol. 19:201-211.

47. ZYSKA, B. 1997. Fungi isolated from library materials: a review of the literature. Int. Biodet. Biodegrad. 40:43-51.

Recibido: Marzo 29 de 2012

Aceptado: Marzo 15 de 2013 